\title{
Vitamins: Friend or Foe
}

Anastasia Shnitser, MD, and Dina Halegoua-De Marzio, MD

\section{Case Presentation}

A 39 year-old male presented to the emergency department with generalized body aches after a recent fall. The patient underwent urgent trauma evaluation and incidentally was found to have multiple medications in his right colon on radiography (Figures 1 and 2). The patient was immediately screened for a drug overdose, but he admitted to taking a large amount of Ultra-Start vitamins that he purchased on the internet. Due to suspicion for possible drug overdose, a nasogastric tube was placed, and polyethylene glycol was administered to help the patient pass the pills from his bowels. Despite the large ingestion of vitamins, the patient remained asymptomatic throughout his hospitalization.

\section{Discussion}

The ability to visualize medications in the gastrointestinal system on imaging depends on the radiodensity of the ingested material. Chloral hydrate, iron-containing preparations, calcium

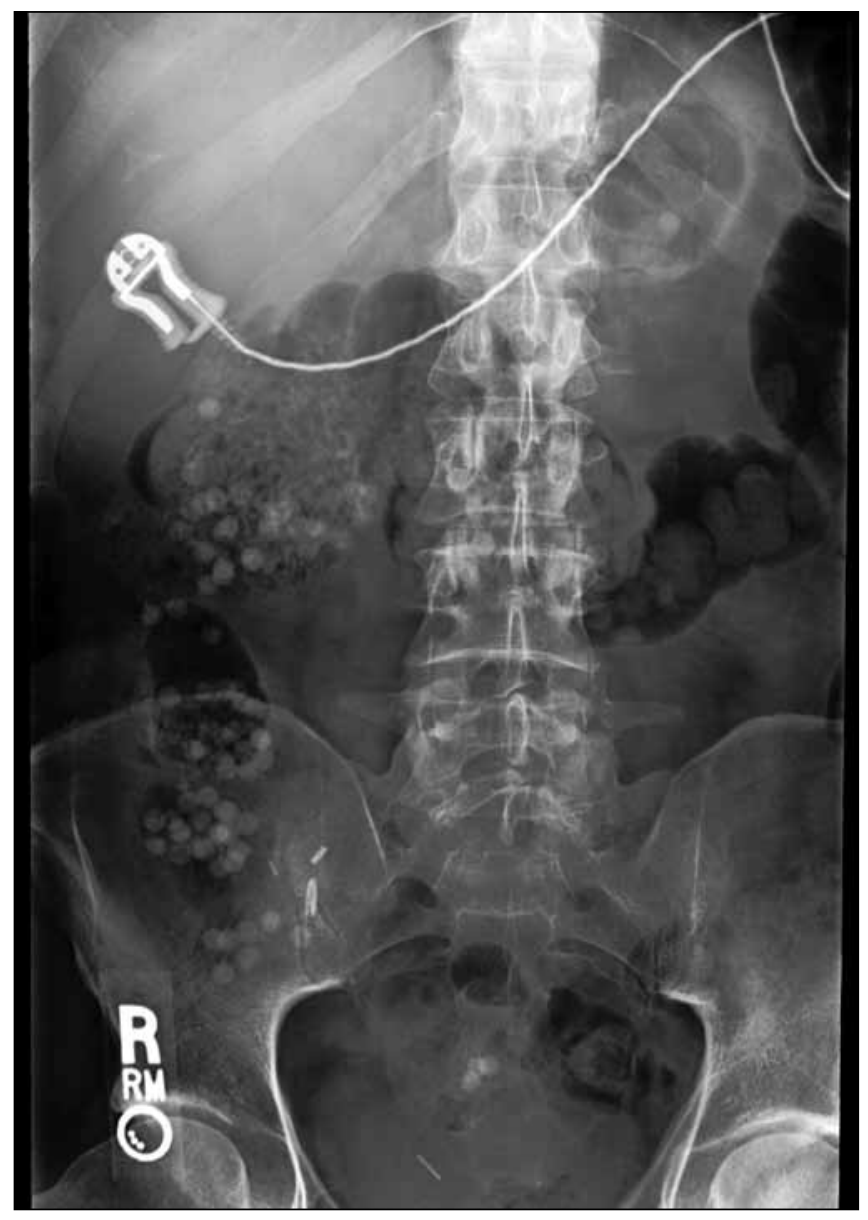

Figure 1. Lumbar X-ray on admission shows the presence of multiple radiopaque pills in the right colon, representing the patient's ingestion of Ultra-Start vitamins.

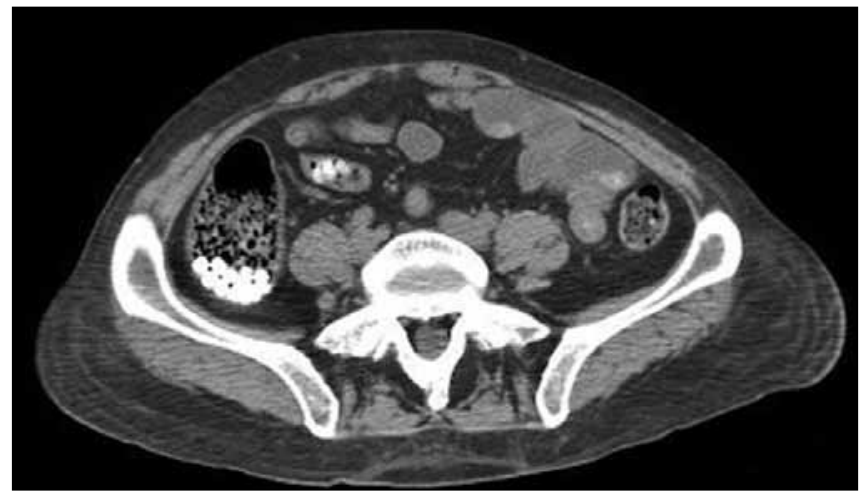

Figure 2. Abdominal CT scan on admission similarly demonstrates that the right colon contains many radiopaque vitamin tablets.

carbonate, iodinated compounds, acetazolamide, busulfan, and potassium-containing preparations are consistently radiopaque. ${ }^{1,2}$ The Ultra-Start vitamins ingested by our patient contained multiple radiodense compounds including iron and calcium carbonate.

There is minimal regulation of the content of nutritional supplements, so patients purchasing vitamins often do not know what they are getting. Some formulations will have extremely poor absorption. Some of the lowest grade nutrients include magnesium oxide, calcium carbonate, vitamins B12, B6, C and D. ${ }^{3}$ The patient in our case was taking vitamins that contained several poorly absorbed combinations.

It is not only important for patients to take the correct vitamin supplementation, but it is important for providers to understand that actual vitamin and mineral amounts often deviate from label values. Potentially toxic levels of vitamins can be achieved easily in people who take high potency vitamins or a large number of pills.

\section{References}

1. Savitt DL, Hawkins HH, Roberts JR. The radiopacity of ingested medications. Ann Emerg Med.1987;16:331-9.

2. Florez MV, Evans JM, Daly TR. The radiodensity of medications seen on x-ray films. Mayo Clin Proc.1998; 73:516-9.

3. Yetley EA. Multivitamin and multimineral dietary supplements: definitions, characterization, bioavailability, and drug interactions. Am J Clin Nutr. 2007; 85:269S-276S. 